\title{
Combined Effects of Six Cytokine Gene Polymorphisms and SNP-SNP Interactions on Hepatocellular Carcinoma Risk in Southern Guangxi, China
}

\author{
Chun-Hua Bei ${ }^{1,2 \&}$, Hua Bai ${ }^{3 \&}$, Hong-Ping Yu², Yan Yang ${ }^{4}$, Qing-Qing Liang ${ }^{2}$, \\ Ying-Ying Deng ${ }^{5}$, Sheng-Kui Tan², Xiao-Qiang Qiu* ${ }^{1 *}$
}

\begin{abstract}
Cytokine gene single nucleotide polymorphisms (SNPs) are involved in the genesis and progression of hepatocellular carcinoma (HCC). We hypothesized that combined effects of cytokine gene SNPs and SNP-SNP interactions are associated with HCC risk. Six SNPs in cytokine genes (IL-2, IFN- $\gamma$, IL-1ß, IL-6, and IL-10) were genotyped in a study of 720 Chinese HCC cases and 784 cancer-free controls. Although none of these SNPs individually had a significant effect on the risk of $\mathrm{HCC}$, we found that the combined effects of these six SNPs may contribute to $\mathrm{HCC}$ risk $(\mathrm{OR}=1.821,95 \% \mathrm{CI}=1.078-3.075)$. This risk was pronounced among smokers, drinkers, and hepatitis B virus carriers. A SNP-SNP interaction between IL-2-330 and IFN- $\gamma-1615$ was associated with an increased HCC risk $(O R=1.078,95 \%$ CI=1.022-1.136). In conclusion, combined effects of SNPs and SNP-SNP interactions in cytokine genes may contribute to $\mathrm{HCC}$ risk.
\end{abstract}

Keywords: Cytokine genes - polymorphisms - interaction - risk - hepatocellular carcinoma - China

Asian Pac J Cancer Prev, 15 (16), 6961-6967

\section{Introduction}

Hepatocellular carcinoma (HCC) is the fifth most common malignancy worldwide, representing more than $85 \%$ of all primary liver cancers (Parikh et al., 2007). About half of all liver cancer deaths were reported to have occurred in China (Jemal et al., 2011). Southern Guangxi has one of the highest occurrences of liver cancer in China, which ranked first in all cancer-related deaths (Zhang et al., 2010). Chronic infection with hepatitis $\mathrm{B}$ virus (HBV) that is perinatally acquired from carrier mothers is a primary cause in China (Yeh et al., 1989). After initial HBV infection, $90 \%$ to $95 \%$ of adults can rely on their own immune systems to clear the virus, causing self-limiting hepatitis. Only $5 \%$ to $10 \%$ of infected individuals develop chronic hepatitis, and $10 \%$ to $25 \%$ of these patients eventually progress to HCC (Lok et al., 2001; lino et al., 2002). This phenomenon suggests that the body's scavenging ability for HBV is based on individual differences. That is, although HBV infection is the major risk factor for $\mathrm{HCC}$, only a fraction of $\mathrm{HBV}$-infected individuals develops HCC. This development behavior suggests that genetic factors may also have important functions in HCC etiology.

Cytokines are a family of proteins that mediate numerous inflammation responses; these proteins contribute to the outcomes of immune-mediated diseases, including HCC (Budhu et al., 2006). Substantial evidence suggests that HCC is inherently associated with the inflammation and up-regulation of cytokines (Bidwell et al., 1999; Li et al., 2010). In the past two decades, epidemiological and genetic evidence has shown that high mutagen sensitivity is a risk factor for cancer development (Wu et al., 2013). Gene regulatory regions, such as promoter regions, contribute to gene functions by binding to specific transcription factors and by regulating gene transcription initiation (Guo et al., 2005). Interleukin 1 beta (IL-1 $\beta$ ) is not only an important host genetic factor but also a key pro-inflammatory cytokine that regulates the expression of several inflammatory molecules (Hwang et al., 2002). Two potentially functional SNPs (-511T/C and $-1464 \mathrm{C} / \mathrm{G})$ in the promoter region of IL- $1 \beta$ can increase IL-1 $\beta$ production (Zeng et al., 2003). The promoter region of IL- $1 \beta$ is reportedly associated with the risk of developing cancers of the lung (Zienolddiny et al., 2004), breast (Liu et al., 2006), liver (Hirankarn et al., 2006), and stomach (El-Omar et al., 2000). IL-2 exerts pleiotropic effects on the immune system by acting as a pro- and anti-inflammatory regulator. The IL-2-330 site is located near an important transcription factor, nuclear factor of

${ }^{1}$ Department of Epidemiology, School of Public Health, Guangxi Medical University, ${ }^{4}$ Department of Endocrinology, JiangBin Hospital of Guangxi, Nanning, ${ }^{2}$ School of Public Health, Guilin Medical University, ${ }^{5}$ Guilin Disease Pevention and Control Center, Guilin, ${ }^{3}$ School of Public Health, Kunming Medical University, Kunming, China ${ }^{\&}$ Equal contributors *For correspondence: xqqiu9999@sina.com 
activated T-cells (NFAT). Thus, this site may influence the activity of transcription factors and subsequently affect the transcription and translation levels of IL-2 (Crabtree et al., 1994; Pyo et al., 2003). Several studies have found that IL-2-330A/C is associated with the risk of genetic susceptibility to nasopharyngeal carcinoma (Wei et al., 2010) and gastric cancer (Sugimoto et al., 2010). Interferon-gamma (IFN- $\gamma$ ), a major cytokine secreted by $\mathrm{T}$ cells, is crucial for anti-viral immune response. The constitutive expression of IFN- $\gamma$ in the liver causes chronic active hepatitis through the recruitment of lymphomononuclear cells (Toyonaga et al., 1994). The expression of IFN- $\gamma$ is slightly higher in HCC tissue than in adjacent normal tissue (Chia et al., 2002). Su et al. (2012) found that IFN- $\gamma$-1615 GA/AA genotypes are significantly related to an elevated risk of breast cancer. IL-10 is a potent immunosuppressive anti-inflammatory cytokine that is highly expressed in HCC tissue and adjacent normal tissue (Chia et al., 2002). IL-10 is the most studied anti-inflammatory cytokine involved in cancer research. The promoter region is highly polymorphic and is associated with gastric cancer and HCC (Shin et al., 2003; Pan et al., 2013). IL-6 is a multifunctional cytokine that serves pro- and anti-inflammatory functions. The level of IL-6 is higher in HCC patients than in healthy individuals (Giannitrapani et al., 2011).

Numerous cytokines participate in the construction of a highly complex and coordinated network in which they modulate their own synthesis and that of other cytokines (Balkwill et al., 1989; Elias et al., 1992). Recent studies have evaluated the effects of individual SNPs but failed to consider the potential combined effects and SNP-SNP interactions in two or more loci. Therefore, one-on-one association cannot sufficiently explain the complexity of disease causality (Onay et al., 2006; Lin et al., 2013). Therefore, we hypothesized that not only the individual effects but also the combined effects of SNPs and SNPSNP interactions in cytokine genes may increase HCC risk. Cytokine gene functional SNPs (rs2069762, rs2069705, rs1143623, rs16944, rs1800769, and rs1800872) were selected to test our hypothesis in this study.

\section{Materials and Methods}

\section{Study population}

All HCC patients and cancer-free controls were recruited from First Affiliated Hospital of Guangxi Medical University, First Affiliated Hospital of Guangxi College of Traditional Chinese Medicine, and First Affiliated Hospital of Guilin Medical University from August 2007 to November 2010. The subjects received a detailed description of the study protocol and signed informed consent forms that were approved by the institutional review board for each medical center. The patients were all newly diagnosed with HCC but had not been treated with radiation, chemotherapy, or surgical therapy before enrollment in the study. The cancer-free controls were recruited in the same period from the Department of Orthopedics and Ophthalmology of the same hospitals. The controls were genetically unrelated visitors or companions of patients and were frequency matched to the cases by age ( \pm 5 years), gender, and nationality (Han, Zhuang, or others). The study protocol was approved by the institutional review board of the Guangxi Cancer Institute.

\section{Data collection}

After informed consent was obtained, a structured interview was conducted by trained interviewers. Data were collected from interviews and reviews of medical records on the demographic characteristics, recent and prior tobacco use, alcohol consumption, and HBV virus markers. Upon consent, $5 \mathrm{~mL}$ of nonheparinized blood was collected from each participant for cytogenetic and molecular genetic analyses. All laboratory and questionnaire data were coded, entered by two investigators, and verified using EpiData 3.1 (www. epidata.dk/download.php). Neither the laboratory nor the data entry personnel had any knowledge of the subjects' case-control status.

\section{Genotyping}

Genomic DNA was extracted from leukocytes using the phenol-chloroform method and stored at $-80^{\circ} \mathrm{C}$. Four SNPs (Table 1) were selected through the SNP info platform (http://snpinfo.niehs.nih.gov/) with the following criteria: the genes were the main cytokine genes involved in the pro-or anti-inflammatory pathways of liver disease, the SNPs were in the transcription factor binding site of the $5^{\prime}$ promoter region, and the pairwise linkage disequilibrium (LD) had a $\mathrm{r}^{2}$ threshold of 0.8 and a minor allele frequency of $5 \%$ or higher in Han Chinese in Beijing (CHB). Considering these criteria, we selected six loci SNPs for genotyping (Table 1). The polymorphisms were genotyped using high-flux TaqMan MGB, a fluorescent quantitative real-time polymerase chain reaction (PCR) method. Each PCR reaction mixture $(25 \mu \mathrm{L})$ contained $1.00 \mu \mathrm{L}$ of DNA template, $10.25 \mu \mathrm{L}$ of $\mathrm{H}_{2} \mathrm{O}, 12.50 \mu \mathrm{L}$ of $2 \times$ TaqMan universal PCR mix, and $1.25 \mu \mathrm{L}$ of $20 \times \mathrm{SNP}$ genotyping assay mix. The genomic DNA was amplified at $95^{\circ} \mathrm{C}$ for $10 \mathrm{~min}$, followed by 40 cycles of $92^{\circ} \mathrm{C}$ for $15 \mathrm{~s}$ and $60^{\circ} \mathrm{C}$ for one min. All genotyping reagents and analytical software were purchased from Applied Biosystems. Genotyping was performed according to the manufacturer's instructions. Approximately 5\% of the samples were randomly repeated to validate the genotyping procedures, and the concordance rate was $100 \%$.

\section{Statistical analysis}

The differences in the distributions of categorical variables, including demographic characteristics, tobacco smoking, and alcohol drinking, and genotype/allele frequencies of selected SNPs between the patients and controls were evaluated using chi-square tests. Crude or adjusted (for age, gender, nationality, smoking, drinking, and HBsAg status) odd ratios (ORs) and $95 \%$ confidence intervals (CIs) were obtained from unconditional univariate and multivariable logistic regression analyses to evaluate the associations between SNPs and HCC risk in the case-control analysis. Data were further stratified by age, gender, nationality, smoking, drinking, and 
Table 1. Candidate Genes and Target SNPs

\begin{tabular}{lllcrr}
\hline Gene & Name & SNP ID & Chromosome position & Polymorphism & MAF $^{\mathrm{a}}$ \\
\hline IL2 & Interleukin-2 & rs2069762 & $4 \mathrm{q} 26-\mathrm{q} 27$ & $-330 \mathrm{~A}>\mathrm{C}$ & $\mathrm{C}: 0.239$ \\
$I F N-\gamma$ & Interferon-gamma & rs2069705 & $12 \mathrm{q} 14$ & $-1615 \mathrm{G}>\mathrm{A}$ & $\mathrm{A}: 0.238$ \\
IL1B & Interleukin-1 beta & rs1143623 & $2 \mathrm{q} 13$ & $-1464 \mathrm{C}>\mathrm{G}$ & $\mathrm{G}: 0.298$ \\
& & rs16944 & $2 \mathrm{q} 13$ & $-511 \mathrm{G}>\mathrm{A}$ & $\mathrm{A}: 0.458$ \\
IL6 & Interleukin-6 & rs1800796 & $7 \mathrm{q} 21$ & $-572 \mathrm{C}>\mathrm{G}$ & $\mathrm{G}: 0.233$ \\
$I L-10$ & Interleukin-10 & rs1800872 & 1q31-32 & $-592 \mathrm{~T}>\mathrm{G}$ & $\mathrm{G}: 0.250$ \\
\hline *ainor allele frequency in CHB according to HapMap database (HapMap Data Release 27 Phase I and II, February 2009, on NCBI B36 assembly, dbSNP126)
\end{tabular}

HBsAg status. Continuous variables were analyzed using Student's t-test and presented as mean \pm SD. HaploView 4.2 was used to test Hardy-Weinberg equilibrium in the control subjects and LD between SNPs in the same gene. The interactions between environmental factors and genomic variants, as well as those between SNPs were qualitatively analyzed with a logistic regression model. All statistical tests were two-sided with a 0.05 significance level, and all data were analyzed with SPSS 13.0 for Windows.

\section{Results}

Characteristics of the study population

This study included $720 \mathrm{HCC}$ patients and 784 controls with available DNA samples. Table 2 presents the frequency distribution of the selected patient and control characteristics. No statistical differences in age and gender distributions were detected between the cases and controls because of the frequency matching by design. The mean age was 47.72 years $( \pm 11.16$, range: 19 years to 81 years $)$ for the controls and 48.65 years $( \pm 11.03$, range: 18 years to 78 years, $P=0.111$ ) for the HCC patients. Approximately $83.3 \%$ and $16.7 \%$ of the controls and $86.0 \%$ and $14.0 \%$ of the patients were male and women, respectively $(P=0.150)$. No significant difference in ethnicity distribution was detected between the cases and controls $(P=0.911)$. However, the prevalence of smoking, drinking, and HBsAg positivity was significantly higher in the patients than in the controls $(P<0.001$ for each). Therefore, smoking, drinking, and HBsAg status were adjusted in the subsequent multivariate logistic regression analyses.

Genotype distribution of polymorphisms of cytokines between patients and controls

The allele and genotype distributions of the studied SNPs in the patients and controls and their associations with HCC risk are summarized in Table 3. All observed genotype distributions among the controls agreed with the Hardy-Weinberg equilibrium $(P>0.05)$. No significant difference in the genotype frequencies of the studied SNPs was found between the patients and controls $(P=0.874$ for IL-2-330A/C $P=0.606$ for IFN- $\gamma-1615 \mathrm{G} / \mathrm{A}, P=0.643$ for IL- $1 \beta-511 \mathrm{C} / \mathrm{T}, P=0.272$ for IL- $1 \beta-1464 \mathrm{C} / \mathrm{G}, P=0.786$ for IL-6-572C/G, and $P=0.101$ for IL-10-592T/G). Although none of the variant genotypes was individually associated with a significantly altered risk, the IL-2-330 AC and CC genotypes were associated with a non-significantly reduced HCC risk (adjusted $\mathrm{OR}=0.93 ; 95 \% \mathrm{CI}=0.72$ to 1.19 for $\mathrm{AC}$, and adjusted $\mathrm{OR}=0.99 ; 95 \% \mathrm{CI}=0.68$ to 1.45 for CC). The AA genotype of IFN- $\gamma-1615$ was associated
Table 2. Demographic Characteristics of HCC Patients and Cancer-free Controls

\begin{tabular}{|c|c|c|c|c|}
\hline Variables & Controls n (\%) & Cases n (\%) & $\mathrm{t} / \chi^{2}$ & $P^{a}$ \\
\hline All Subjects & $784(100)$ & $720(100)$ & & \\
\hline Age & $47.72 \pm 11.16$ & $48.65 \pm 11.03$ & 1.62 & 0.111 \\
\hline$<40$ & $147(18.8)$ & $156(21.7)$ & 2.50 & 0.287 \\
\hline 40 to 55 & $427(54.4)$ & $367(51.0)$ & & \\
\hline$>55$ & $210(26.8)$ & $197(27.3)$ & & \\
\hline Gender & & 2.07 & 0.150 & \\
\hline Male & $653(83.3)$ & $619(86.0)$ & & \\
\hline Female & $131(16.7)$ & $101(14.0)$ & & \\
\hline Nationality & & & 0.19 & 0.911 \\
\hline Han & $557(71.0)$ & $512(71.1)$ & & \\
\hline Zhuang & $218(27.8)$ & $198(27.5)$ & & \\
\hline Other & $9(1.2)$ & $10(1.4)$ & & \\
\hline Smoking & & 113.69 & $<0.001$ & \\
\hline No & $669(85.3)$ & $440(61.1)$ & & \\
\hline Yes & 115 (14.7) & $280(38.9)$ & & \\
\hline Alcohol drinking & & & 125.66 & $<0.001$ \\
\hline No & $671(85.6)$ & $432(60.0)$ & & \\
\hline Yes & $113(14.4)$ & $288(40.0)$ & & \\
\hline HBsAg status & & & 265.14 & $<0.001$ \\
\hline$(-)$ & $494(63.0)$ & $154(31.4)$ & & \\
\hline$(+)$ & $290(37.0)$ & $566(78.6)$ & & \\
\hline
\end{tabular}

Table 4. Association of Combined Risk Genotypes and HCC Risk

\begin{tabular}{lrrrc}
\hline $\begin{array}{l}\text { Number of combined } \\
\text { risk genotype }\end{array}$ & Control & Case & $P$ & OR $(95 \% \mathrm{CI})^{\mathrm{b}}$ \\
\hline $0-1$ & $53(6.76)$ & $36(5.00)$ & 0.025 & 1 \\
$2-3$ & $441(56.25)$ & $409(56.81)$ & 1.576 \\
& & & $(0.945-2.628)$ \\
$4-6$ & $290(36.99)$ & $275(38.19)$ & 1.821 \\
& & & $(1.078-3.075)$ \\
\hline
\end{tabular}

*a. Number of risk genotypes used in calculation and assumed risk genotypes used for calculation (i.e., IL-2-330AA, IFN- $\gamma$-1615AG/AA, IL-1 $\beta-511 C T / T T$, IL-1 $\beta-1464$ CG/GG, IL-6-572 GG/CG, and IL-10 -592TG/GG). b. Adjusted for age, gender, nationality, smoking, alcohol drinking, and HBsAg status

with a non-significantly increased $\mathrm{HCC}$ risk $(\mathrm{OR}=1.36$; $95 \% \mathrm{CI}=0.92$ to 2.01 ). The $\mathrm{CT}$ and TT genotypes of IL-1 $\beta$ -511 were associated with a non-significantly increased $\mathrm{HCC}$ risk (adjusted $\mathrm{OR}=1.31 ; 95 \% \mathrm{CI}=0.98$ to 1.74 for $\mathrm{CT}$, and adjusted $\mathrm{OR}=1.17 ; 95 \% \mathrm{CI}=0.84$ to 1.63 for TT). The GG genotype of IL-1 $\beta-1464 \mathrm{G} / \mathrm{C}$ was associated with a non-significantly reduced $\mathrm{HCC}$ risk (adjusted $\mathrm{OR}=0.84$; $95 \% \mathrm{CI}=0.60$ to 1.17 ). The genotypes of IL-6-572C/G and IL-10-819T/G were associated with a non-significantly increased $\mathrm{HCC}$ risk (adjusted $\mathrm{OR}=1.05 ; 95 \% \mathrm{CI}=0.82$ to 1.34 for $\mathrm{CG} / \mathrm{GG}$, and adjusted $\mathrm{OR}=1.03 ; 95 \% \mathrm{CI}=0.82$ to 1.30 for $\mathrm{TG} / \mathrm{GG}$, respectively).

We combined the SNPs by the number of the putative risk genotypes (i.e., IL-2-330AA, IFN- $\gamma$-1615AG/AA, IL-1 $\beta-511 \mathrm{CT} / \mathrm{TT}, \mathrm{IL}-1 \beta-1464 \mathrm{CG} / \mathrm{GG}, \mathrm{IL}-6-572 \mathrm{GG} / \mathrm{CG}$, and IL-10-592TG/GG) to assess their possible combined 
Table 3. Genotype and Allele Frequency Polymorphisms Among Controls And Patients, and their Associations with HCC Risk

\begin{tabular}{|c|c|c|c|c|c|c|}
\hline \multicolumn{2}{|c|}{ Variant genotypes } & \multirow{2}{*}{$\frac{\text { Controls } \mathrm{n}=784(\%)}{311(39.7)}$} & \multirow{2}{*}{$\frac{\text { Cases } n=720(\%)}{292(40.6)}$} & \multirow{2}{*}{$\frac{\chi^{2 \mathrm{a}}}{0.27}$} & \multirow{2}{*}{$\frac{P^{a}}{0.874}$} & \multirow{2}{*}{$\frac{\mathrm{OR}(95 \% \mathrm{CI})^{\mathrm{b}}}{1}$} \\
\hline$I L-2-330$ & AA & & & & & \\
\hline & $\mathrm{AC}$ & $373(47.6)$ & $333(46.2)$ & & & $0.93(0.72-1.19)$ \\
\hline & $\mathrm{CC}$ & $100(12.7)$ & $95(13.2)$ & & & $0.99(0.68-1.45)$ \\
\hline & $\mathrm{AC} / \mathrm{CC}$ & $473(60.3)$ & $428(59.4)$ & & & $0.94(0.74-1.20)$ \\
\hline & A & $573(36.5)$ & $523(33.4)$ & 0.02 & 0.899 & \\
\hline \multirow[t]{5}{*}{$I F N-\gamma-1615$} & GG & $384(49.0)$ & 357 (49.6) & 1.01 & 0.606 & 1 \\
\hline & $\mathrm{AG}$ & $318(40.6)$ & 278 (38.6) & & & $0.95(0.74-1.22)$ \\
\hline & $\mathrm{AA}$ & $82(10.4)$ & $85(11.8)$ & & & $1.36(0.92-2.01)$ \\
\hline & $\mathrm{AG} / \mathrm{AA}$ & $400(51.0)$ & $363(50.4)$ & & & $1.02(0.81-1.29)$ \\
\hline & $\mathrm{G}$ & $1086(65.5)$ & 992 (63.3) & 0.04 & 0.826 & \\
\hline \multirow[t]{5}{*}{$I L 1 B-511$} & $\mathrm{CC}$ & $206(26.3)$ & $174(24.2)$ & 0.88 & 0.643 & 1 \\
\hline & $\mathrm{CT}$ & $384(49.0)$ & $363(50.4)$ & & & $1.31(0.98-1.74)$ \\
\hline & $\mathrm{TT}$ & $194(24.7)$ & $183(25.4)$ & & & $1.17(0.84-1.63)$ \\
\hline & $\mathrm{CT} / \mathrm{TT}$ & $578(73.7)$ & $546(75.8)$ & & & $1.26(0.96-1.65)$ \\
\hline & $\mathrm{C}$ & $772(49.3)$ & $729(46.5)$ & 0.58 & 0.446 & \\
\hline \multirow[t]{5}{*}{$I L 1 B-1464$} & $\mathrm{CC}$ & $238(30.4)$ & $214(29.7)$ & 2.6 & 0.272 & 1 \\
\hline & $\mathrm{CG}$ & $367(46.8)$ & $363(50.4)$ & & & $1.28(0.97-1.67)$ \\
\hline & GG & $179(22.8)$ & 143 (19.9) & & & $0.84(0.60-1.17)$ \\
\hline & $\mathrm{CG} / \mathrm{GG}$ & $546(69.6)$ & $506(70.3)$ & & & $1.24(0.95-1.64)$ \\
\hline & $\mathrm{C}$ & $843(53.8)$ & $791(54.9)$ & 0.41 & 0.521 & \\
\hline \multirow[t]{5}{*}{$I L-6-572$} & $\mathrm{CC}$ & $523(66.7)$ & $485(67.4)$ & 0.48 & 0.786 & 1 \\
\hline & $\mathrm{CG}$ & $232(29.6)$ & $213(29.5)$ & & & $0.88(0.46-1.69)$ \\
\hline & GG & $29(3.7)$ & $22(3.1)$ & & & $1.07(0.83-1.38)$ \\
\hline & $\mathrm{CG} / \mathrm{GG}$ & $261(33.3)$ & $235(32.6)$ & & & $1.05(0.82-1.34)$ \\
\hline & $\mathrm{C}$ & $1278(81.5)$ & $1183(75.4)$ & 0.21 & 0.605 & \\
\hline \multirow[t]{5}{*}{$I L-10-592$} & TT & $392(50.0)$ & $356(49.2)$ & 4.58 & 0.101 & 1 \\
\hline & $\mathrm{TG}$ & 313 (39.9) & $312(43.3)$ & & & $0.67(0.43-1.06)$ \\
\hline & GG & $79(10.1)$ & $52(7.5)$ & & & $1.01(0.88-1.46)$ \\
\hline & TG/GG & 705 (89.9) & $668(92.5)$ & & & $1.03(0.82-1.30)$ \\
\hline & $\mathrm{T}$ & $1091(69.6)$ & $1020(65.1)$ & 0.56 & 0.453 & \\
\hline
\end{tabular}

$* \mathrm{a} \chi^{2}$ and $P$ value for two-sided Chi-square test. $* * \mathrm{~b}$ Adjusted for age, gender, nationality, smoking, alcohol drinking, and HBsAg status.

Table 5. Association and Stratification Analysis of Combined Genotypes of IL-2, IFN- $\gamma$, IL-1ß, IL-6, and IL-10 Polymorphisms and HCC Risk

\begin{tabular}{|c|c|c|c|c|c|c|c|}
\hline & & Number & mbined & genotype & SNP on & ed cytokine genes & \\
\hline Variables & control/ca & & & control/c & & Adjusted & $(95 \% \mathrm{CI})^{\mathrm{a}}$ \\
\hline & & & $0 \sim 1$ & $2 \sim 3$ & $4 \sim 6$ & $0 \sim 1$ verse $2 \sim 3$ & $0 \sim 1$ verse $4 \sim 6$ \\
\hline Age (years) & $<40$ & $147 / 156$ & $29 / 22$ & $52 / 68$ & $66 / 66$ & $1.092(0.750-2.749)$ & $2.767(0.650-3.777)$ \\
\hline & $40-55$ & $427 / 367$ & $79 / 58$ & $171 / 139$ & $177 / 170$ & $1.595(0.784-3.244)$ & $1.802(0.869-3.736)$ \\
\hline & $>55$ & $210 / 197$ & $33 / 32$ & $84 / 82$ & $93 / 83$ & $1.223(0.428-3.492)$ & $1.565(0.538-4.554)$ \\
\hline Gender & Female & $131 / 101$ & $19 / 16$ & $53 / 54$ & $59 / 40$ & $1.943(0.503-7.512)$ & $1.330(0.331-5.345)$ \\
\hline & Male & $653 / 619$ & $122 / 96$ & $254 / 244$ & $277 / 279$ & $1.477(0.846-2.577)$ & $1.906(1.077-3.371)$ \\
\hline Nationality & Han & $557 / 512$ & $97 / 86$ & $217 / 204$ & $243 / 222$ & $1.413(0.804-2.481)$ & $1.642(0.921-2.928)$ \\
\hline & Zhuang & $227 / 208$ & $44 / 26$ & $90 / 85$ & $93 / 97$ & $2.165(0.605-7.775)$ & $2.502(0.681-9.200)$ \\
\hline Smoking & No & $115 / 280$ & $17 / 52$ & $44 / 109$ & $54 / / 119$ & $1.118(0.448-2.789)$ & $0.875(0.342-2.240)$ \\
\hline & Yes & $669 / 440$ & $124 / 60$ & $263 / 180$ & $282 / 200$ & $1.892(0.992-3.609)$ & $2.497(1.293-4.822)$ \\
\hline Alcohol drinking & No & $113 / 288$ & $14 / 50$ & $43 / 121$ & $56 / 117$ & $0.972(0.371-2.552)$ & $0.883(0.327-2.384)$ \\
\hline & Yes & $671 / 432$ & $127 / 62$ & $264 / 168$ & $280 / 202$ & $2.019(1.067-3.820)$ & $2.483(1.297-4.757)$ \\
\hline $\mathrm{HBsAg}$ & $(-)$ & $290 / 566$ & $57 / 94$ & $112 / 235$ & $121 / 237$ & $0.847(0.354-1.026)$ & $1.052(0.434-2.549)$ \\
\hline & $(+)$ & $494 / 154$ & $84 / 18$ & $195 / 54$ & $215 / 82$ & $1.958(1.067-3.594)$ & $2.122(1.134-3.971)$ \\
\hline
\end{tabular}

*a. Adjusted for age, gender, nationality, smoking, alcohol drinking, and HBsAg status

effects on HCC risk. The combined risk genotypes were statistically associated with an increased HCC risk $(\mathrm{OR}=1.821 ; 95 \% \mathrm{CI}=1.078$ to 3.075$)$ (Table 4$)$.

Association and stratification analysis forcombined genotypes of cytokine gene polymorphisms and HCC risk

After further stratification by age, gender, nationality, smoking, alcohol drinking, and HBsAg status, an increased risk associated with the combined genotype with four to six risk genotypes was pronounced in persistent smokers ( $\mathrm{OR}=2.497 ; 95 \% \mathrm{CI}=1.293$ to 4.822 ), persistent drinkers $(\mathrm{OR}=2.483 ; 95 \% \mathrm{CI}=1.297$ to 4.757$)$, and $\mathrm{HBsAg}$-positive individuals $(\mathrm{OR}=2.122 ; 95 \% \mathrm{CI}=1.134$ to 3.971) (Table 5).

\section{Evaluation of SNP-SNP interactions}

Considering the possible interaction effects among the six SNPs and environmental factors on HCC risk, we further assessed the interactions of these SNPs 
Table 6. Interaction Effects of IL-2, IFN- $\gamma$, IL-1ß, IL-6, and IL-10 Polymorphisms on HCC Risk

\begin{tabular}{|c|c|c|c|c|}
\hline SNP $\times$ SNP interaction & SE & Wald & $P$ & OR $(95 \% \mathrm{CI})^{\mathrm{a}}$ \\
\hline $\begin{array}{l}I L-2-330 A>C * \\
I F N-\gamma-1615 G / A\end{array}$ & 0.138 & 4.213 & 0.005 & $1.078(1.022-1.136)$ \\
\hline $\begin{array}{l}I L-2-330 A>C * \\
I L-1 \beta-1464 C / G\end{array}$ & 0.280 & 0.045 & 0.833 & $1.061(0.613-1.836)$ \\
\hline $\begin{array}{l}I L-2-330 A>C * \\
I L-1 \beta-511 C / T\end{array}$ & 0.265 & 1.375 & 0.241 & $1.364(0.812-2.292)$ \\
\hline $\begin{array}{l}I L-2-330 A>C * \\
I L-6-572 C>G\end{array}$ & 0.043 & 3.223 & 0.073 & $1.080(0.993-1.175)$ \\
\hline $\begin{array}{l}I L-2-330 A>C * \\
I L-10-592 T>G\end{array}$ & 0.040 & 0.192 & 0.662 & $0.982(0.908-1.063)$ \\
\hline $\begin{array}{l}I F N-\gamma-1615 G / A \\
I L-1 \beta-1464 C / G\end{array}$ & 0.126 & 0.048 & 0.826 & $0.944(0.567-1.573)$ \\
\hline $\begin{array}{l}I F N-\gamma-1615 G / A * \\
I L-1 \beta-511 C / T\end{array}$ & 0.031 & 0.001 & 0.996 & $1.000(0.942-1.062)$ \\
\hline $\begin{array}{l}I F N-\gamma-1615 G / A * \\
I L-6-572 C>G\end{array}$ & 0.042 & 0.236 & 0.627 & $1.021(0.940-1.109)$ \\
\hline $\begin{array}{l}I F N-\gamma-1615 G / A * \\
I L-10-592 T>G\end{array}$ & 0.040 & 0.680 & 0.410 & $1.033(0.896-1.117)$ \\
\hline $\begin{array}{l}I L-1 \beta-1464 C / G^{*} \\
I L-1 \beta-511 C / T\end{array}$ & 0.092 & 0.524 & 0.469 & $1.069(0.892-1.281)$ \\
\hline $\begin{array}{l}I L-1 \beta-1464 C / G \\
I L-6-572 C>G\end{array}$ & 0.049 & 0.088 & 0.767 & $0.986(0.896-1.085)$ \\
\hline $\begin{array}{l}I L-1 \beta-1464 C / G * \\
I L-10-592 T>G\end{array}$ & 0.043 & 0.264 & 0.688 & $0.978(0.899-1.054)$ \\
\hline $\begin{array}{l}I L-1 \beta-511 C / T^{*} \\
I L-6-572 C>G\end{array}$ & 0.046 & 0.041 & 0.841 & $1.009(0.922-1.105)$ \\
\hline $\begin{array}{l}I L-1 \beta-511 C / T * \\
I L-10-592 T>G\end{array}$ & 0.052 & 0.504 & 0.479 & $1.029(0.852-1.081)$ \\
\hline $\begin{array}{l}I L-6-572 C>G^{*} \\
I L-10-592 T>G\end{array}$ & 0.063 & 0.824 & 0.364 & $0.944(0.834-1.069)$ \\
\hline
\end{tabular}

*a.Adjusted for age, gender, nationality, smoking, alcohol drinking, and HBsAg status.

and environmental factors, such as smoking, drinking, and HBsAg positivity in HCC. However, no statistical evidence was found for interactions among these variables in the multivariate logistic regression models (data not shown). In addition, SNP-SNP interaction between IL2-330 and IFN- $\gamma-1615$ was associated with an increased $\mathrm{HCC}$ risk $(\mathrm{OR}=1.078,95 \% \mathrm{CI}=1.022$ to 1.136$)$. SNPSNP interactions were not observed in any other SNPs (Table 6).

\section{Discussion}

In the $720 \mathrm{HCC}$ patients and 784 cancer-free controls, none of the six SNPs in cytokine genes (IL-2-330A/C, IFN- $\gamma-1615 \mathrm{G} / \mathrm{A}$, IL-1 $\beta-511 \mathrm{C} / \mathrm{T}, \mathrm{IL}-1 \beta-1464 \mathrm{C} / \mathrm{G}$, IL-6$572 \mathrm{C} / \mathrm{G}$, and IL-10-592T/G) was individually associated with HCC risk. Rather, the combined effects of these SNPs increased HCC risk among smokers, drinkers, and HBsAg-positive individuals. These findings support our hypothesis that the effect of an individual SNP is generally not significant and that the genetic combined effects of SNPs and SNP-SNP interactions increase HCC risk.

Numerous studies have investigated the relations between cytokine polymorphisms and HCC risk; however, their results are controversial (Shin et al., 2003; Hirankarn et al., 2006; Slattery et al., 2007). Two studies have consistently noted that IL- $1 \beta-511$ polymorphisms are significant risk factors for HCC progression in the Thai population and in Japanese patients (Tanaka et al., 2003; Hirankarn et al., 2006). However, a recent meta-analysis has reported that IL-1 $\beta-511 \mathrm{C} / \mathrm{T}$ is not significantly associated with HCC risk in an Asian population (Yang et al., 2011). And a recent study has suggested the lack of association of selected seven cytokine gene polymorphisms with the risk of HCC recurrence in Han Chinese population (Wu et al., 2013). Previous studies evaluated the effects of individual SNP or single one gene on the HCC risk and failed to consider the potential combined effects of these SNPs on different genes (Tanaka et al., 2003; Hirankarn et al., 2006; Pan et al., 2013). In the present study, no individual SNP was significantly associated with HCC risk. It is likely that the effect of single SNP on HCC risk may be modest and undetectable. Alternatively, the effect of a single SNP may be influenced by that of other gene SNPs. In this study, we found that individuals with four to six risk genotypes (i.e., IL-2-330AA, IFN- $\gamma-1615 \mathrm{AG} /$ AA, IL-1 $\beta-511 C T / T T$, IL-1 $\beta-1464 C G / G G$, IL-6-572GG/ CG, and IL-10-592TG/GG) may have an increased HCC risk. Consistent with the result of Nieters et al. (2005), the present study found that the synergistic rather than the individual effects of cytokine gene SNPs were associated with an increased HCC risk.

HCC is a multi-factorial disease that results from complex interactions between environmental and genetic factors. Therefore, we speculated that hereditary factors and environmental factors (smoking, drinking, and HBsAg positivity) increase HCC risk. Compared with individuals who never smoked or drank, smokers and drinkers had a significantly higher $\mathrm{HCC}$ risk, which was associated with the combined effects of the putative high-risk genotypes in cytokine genes (Table 5). Similar conclusions have been previously attained. Chen et al. (2005) have reported that smoking modifies the combined effects of multiple loci in the cytokine and DNA repair genes. Cigarette smoking is reportedly associated with an increased HCC risk in HBsAg carriers, and this association is independent of geography and ethnicity (El-Zayadi et al., 2006; Koh et al., 2011). Cigarette consists of over 4000 toxic substances, which cause adverse effects on the immune system (Zhang et al., 2014). Excessive alcohol consumption is a well-established risk factor for liver disease and HCC (Morgan et al., 2004). These results, together with our findings, suggest that smoking and drinking promote HCC progression. Previous epidemiological studies have found that chronic infection with $\mathrm{HBV}$ is a major etiological risk factor for HCC in China (Yeh et al., 1986; Groopman et al., 1996). Expectedly, the combined effects of cytokine gene SNPs with HBV infection increased HCC risk. However, we did not find statistical evidence on the interactions among these variables possibly because of the limited sample size.

The present study showed that the interaction between IL-2-330A/C and IFN- $\gamma$-1615G/A was significantly associated with $\mathrm{HCC}$ risk. This result indicates that the individual effect of IL-2-330A/C or IFN- $\gamma-1615$ G/A is generally minimal and SNP-SNP interaction increases HCC risk. Ikeguchi et al. (2005) evaluated the gene expression levels of IL-2 in HCC patients and found that IL-2 expression may be an important prognostic biomarker for HCC. However, it was reported that the distribution of IL-2 -330A/C genotypes between HCC patients and healthy people had no statistical difference (Ognjanovic 
et al., 2009). IFN- $\gamma$ was detected in HCC, and the authors concluded that IFN- $\gamma$ may not play a large role in liver inflammation (Tangkijvanich et al., 2000). Similar to that, no significant differences were found in IL-2-330 and IFN- $\gamma$-1615 genotype distribution in Guangxi people of China between HCC patients and controls in this study. Although IL-2-330 and IFN- $\gamma-1615$ are located on different genes, their positions are considerably near (rs2069762 and rs2069705). Therefore, their locations may affect their biological functions through interactions. To date, SNP-SNP interactions between different cytokine genes and HCC risk have not yet been reported. Further studies with large sample sizes are necessary to confirm our findings.

To the best of our knowledge, this study is the first to investigate the association between cytokine gene SNPSNP interactions and HCC risk. We found that SNP-SNP interactions between SNPs that did not exert individual effects on HCC risk were associated with HCC occurrence. Previous studies investigated SNP-SNP interactions during the development of breast cancer (Sapkota et al., 2013) and colorectal cancer (Goodman et al., 2006). These reports support our findings regarding the effects of SNP-SNP interactions on HCC risk. That is, SNPs with negligible effects may interact with other SNPs to increase HCC risk. In this study, potential confounding factors, such as age, gender, and nationality, were matched between the patients and controls to decrease possible biases. Furthermore, our results were based on adjusted estimates. The analyses were adjusted for other covariates, including smoking, alcohol drinking, and HBsAg status. However, several potential limitations in this study should be considered. Firstly, six SNPs were included in the analyses, and the possibility of false-positive associations could not be ruled out because of multiple tests. Secondly, this study excluded several other cytokine SNPs, such as TNF-A-308 and IL-10-819 polymorphisms (Budhu et al., 2006), which might affect HCC risk. Thirdly, the number of current studies was relatively small. Therefore, further investigations involving subjects of different races must be conducted to clarify this relationship. Despite these limitations, our findings are biologically plausible. Therefore, more risk polymorphisms of HCC should be induced as covariants to conclude an accurate effect.

In summary, none of the six SNPs of IL-2-330A/C,

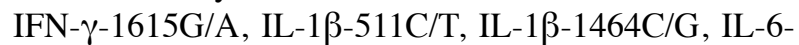
$572 \mathrm{C} / \mathrm{G}$, and IL-10-592T/G was individually associated with HCC risk. However, their combined effects and interactions may have important functions in HCC development in the high-risk regions in China. The cytokine-coordinated network system is so comprehensive that analyzing only a single pathway may be limiting. Therefore, further independent studies of multiple pathways with large sample sizes and relatively functional studies are needed to validate the current findings.

\section{Acknowledgements}

This work were supported by a grant from the National Natural Science Foundation of China (No. 30860247) and Guangxi Zhuang Autonomous Region university scientific research project (2014, No.8). We thank Jin-Mei Huang, Xue-Jiao Fan, Long-Ji, Long-Man Li for assistance in the sample collection.

\section{References}

Abdel Rahim BE, Mahfouz MS, Yagoub U, et al (2014). Practice and attitude of cigarette smoking: a community-based study. PLoS One, 9, 92939.

Balkwill FR, Burke F (1989). The cytokine network. Immunol Today, 10, 299-304.

Bidwell J, Keen L, Gallagher G., et al (1999). Cytokine gene polymorphism in human disease: on-line databases. Genes Immun, 1, 3-19.

Boehm U, Klamp T, Groot M, et al (1997). Cellular responses to interferon-gamma. Annu Rev Immunol, 15, 749-95.

Budhu A, Wang XW (2006). The role of cytokines in hepatocellular carcinoma. J Leukoc Biol, 80, 1197-213.

Chen CC, Yang SY, Liu CJ, et al (2005). Association of cytokine and DNA repair gene polymorphisms with hepatitis B-related hepatocellular carcinoma. Int J Epidemiol, 34, 1310-8.

Chia CS, BanK, Ithnin H, et al (2002). Expression of interleukin-18, interferon-gamma and interleukin-10 in hepatocellular carcinoma. Immunol Lett, 84, 163-72.

Crabtree GR, Clipstone NA (1994). Signal transmission between the plasma membrane and nucleus of T lymphocytes. Annu Rev Biochem, 63, 1045-83.

El-Omar EM, Carrington M, Chow WH, et al (2000). Interleukin-1 polymorphisms associated with increased risk of gastric cancer. Nature, 404, 398-402.

El-Zayadi AR (2006). Heavy smoking and liver. World $J$ Gastroenterol, 12, 6098-101.

Elias JA, Zitnik RJ (1992). Cytokine-cytokine interactions in the context of cytokine networking. Am J Respir Cell Mol Bio, 7, 365-7.

Giannitrapani L, Soresi M, Giacalone A, et al (2011). IL-6 $-174 \mathrm{G} / \mathrm{C}$ polymorphism and IL-6 serum levels in patients with liver cirrhosis and hepatocellular carcinoma. OMICS, 15, 183-6.

Goodman JE, Mechanic LE, Luke BT, et al (2006). Exploring SNP-SNP interactions and colon cancer risk using polymorphism interaction analysis. Int J Cancer, 118, 1790-7.

Groopman JD, Wang JS, Scholl P (1996). Molecular biomarkers for aflatoxins: from adducts to gene mutations to human liver cancer. Can J Physiol Pharmacol, 74, 203-9.

Guo Y, Jamison DC (2005). The distribution of SNPs in human gene regulatory regions. BMC Genomics, 6, 140.

Hirankarn N, Kimkong I, Kummee P, et al (2006). Interleukin1 beta gene polymorphism associated with hepatocellular carcinoma in hepatitis B virus infection. World $J$ Gastroenterol, 12, 776-9.

Hwang IR, Kodama T, Kikuchi S, et al (2002). Effect of interleukin 1 polymorphisms on gastric mucosal interleukin 1beta production in helicobacter pylori infection. Gastroenterology, 123, 1793-803.

Ikeguchi M, Hirooka Y (2005). Interleukin-2 gene expression is a new biological prognostic marker in hepatocellular carcinomas. Onkologie, 28, 255-9.

Iino S (2002). Natural history of hepatitis B and C virus infections. Oncology, 62, 18-23.

Jemal A, Bray F, Center MM, et al (2011). Global cancer statistics. CA Cancer J Clin, 61, 69-90.

Koh WP, Robien K, Wang R, et al (2011). Smoking as an independent risk factor for hepatocellular carcinoma: the Singapore Chinese Health Study. Br J Cancer, 105, 1430-5.

Li F, Wang Z, Liu Y, et al (2010). Down-regulation of 
fractalkine inhibits the in vitro and in vivo angiogenesis of the hepatocellular carcinoma HepG2 cells. Oncol Rep, 24, 669-75.

Lin HY, Amankwah EK, Tseng TS, et al (2013). SNP-SNP interaction network in angiogenesis genes associated with prostate cancer aggressiveness. PLoS One, 8, 59688.

Liu J, Zhai X, Jin G, et al (2006). Functional variants in the promoter of interleukin-1beta are associated with an increased risk of breast cancer: a case-control analysis in a Chinese population. Int J Cancer, 118, 2554-8.

Lok AS, Heathcote EJ, Hoofnagle JH (2001). Management of hepatitis B: 2000-summary of a workshop. Gastroenterology, 120, 1828-53.

Morgan TR, Mandayam S, Jamal M.M. (2004). Alcohol and hepatocellular carcinoma. Gastroenterology, 127, 87-96.

Nieters A, Yuan JM, Sun CL, et al (2005). Effect of cytokine genotypes on the hepatitis B virus-hepatocellular carcinoma association. Cancer, 103, 740-8.

Onay V.U, Briollais L, Knight J.A, et al (2006). SNP-SNP interactions in breast cancer susceptibility. BMC Cancer, 6, 114.

Pan XF, Yang SJ, Loh M, et al (2013). Interleukin-10 gene promoter polymorphisms and risk of gastric cancer in a Chinese population: single nucleotide and haplotype analyses. Asian Pac J Cancer Prev, 14, 2577-82.

Parikh S, Hyman D (2007). Hepatocellular cancer: a guide for the internist. Am J Med, 120, 194-202.

Pyo CW, Hur SS, Kim YK, et al (2003). Polymorphisms of IL-1B, IL-1RN, IL-2, IL-4, IL-6, IL-10, and IFN-gamma genes in the Korean population. Hum Immunol, 64, 979-89.

Sapkota Y, Mackey JR, Lai R, et al (2013). Assessing SNPSNP interactions among DNA repair, modification and metabolism related pathway genes in breast cancer susceptibility. PLoS One, 8, 64896.

Shin HD, Park BL, Kim LH, et al (2003). Interleukin 10 haplotype associated with increased risk of hepatocellular carcinoma. Hum Mol Genet, 12, 901-6.

Slattery M.L, Wolff R.K, Herrick J.S, et al (2007) IL6 genotypes and colon and rectal cancer. Cancer Causes Control, 18, 1095-105.

Su Y, Tang LY, Chen LJ, et al (2012). Joint effects of febrile acute infection and an interferon-gamma polymorphism on breast cancer risk. PLoS One, 7, 37275.

Sugimoto M, Yamaoka Y, Furuta T (2010). Influence of interleukin polymorphisms on development of gastric cancer and peptic ulcer. World J Gastroenterol, 16, 1188-200.

Tanaka Y, Furuta T, Suzuki S, et al (2003). Impact of interleukin1beta genetic polymorphisms on the development of hepatitis C virus-related hepatocellular carcinoma in Japan. J Infect Dis, 187, 1822-5.

Tangkijvanich P, Vimolket T, Theamboonlers A, et al (2000). Serum interleukin- 6 and interferon-gamma levels in patients with hepatitis B-associated chronic liver disease. Asian Pac J Allergy Immunol, 18, 109-114

Toyonaga T, Hino O, Sugai S, et al (1994). Chronic active hepatitis in transgenic mice expressing interferon-gamma in the liver. Proc Natl Acad Sci U S A, 91, 614-8.

Wei YS, Lan Y, Zhang L, et al (2010). Association of the interleukin-2 polymorphisms with interleukin-2 serum levels and risk of nasopharyngeal carcinoma. DNA Cell Biol, 29, 363-8.

Wu LM, Zhou L, Xu J, et al (2013). Lack of association between genetic polymorphisms in cytokine genes and tumor recurrence in patients with hepatocellular carcinoma undergoing transplantation. Hepatobiliary Pancreat Dis Int, 12, 54-9.

Wu X, Gu J, Spitz M R (2007). Mutagen sensitivity: a genetic predisposition factor for cancer. Cancer Res, 67, 3493-5.

Yang Y, Luo C, Feng R. \& Bi S, et al (2011). The TNF-alpha, IL-1B and IL-10 polymorphisms and risk for hepatocellular carcinoma: a meta-analysis. J Cancer Res Clin Oncol, 137, 947-52.

Yeh FS, Yu MC, Mo CC, et al (1989). Hepatitis B virus, aflatoxins, and hepatocellular carcinoma in southern Guangxi, China. Cancer Res, 49, 2506-9.

Yen FS, Shen KN (1986). Epidemiology and early diagnosis of primary liver cancer in China. Adv Cancer Res, 47, 297-329.

Zeng ZR, Hu PJ, Hu S, et al (2003). Association of interleukin $1 \mathrm{~B}$ gene polymorphism and gastric cancers in high and low prevalence regions in China. Gut, 52, 1684-9.

Zhang CY, Huang TR, Yu JH, et al (2010). Epidemiological analysis of primary liver cancer in the early $21^{\text {st }}$ century in Guangxi province of China. Chin J Cancer, 29, 545-50.

Zhang XF, Wei T, Liu X.M, et al (2014). Impact of cigarette smoking on outcome of hepatocellular carcinoma after surgery in patients with hepatitis B. PLoS One, 9, 85077.

Zienolddiny S, Ryberg D, Maggini V, et al (2004). Polymorphisms of the interleukin-1 beta gene are associated with increased risk of non-small cell lung cancer. Int J Cancer, 109, 353-6. 